\title{
EL SUMAK KAWSAY Y EL YASUNÍ: CONTRADICCIONES, DISPUTAS Y ESPERANZAS. UNA ALTERNATIVA AL CAPITALISMO
}

\section{O SUMAK KAWSAY E O YASUNÍ: CONTRADIÇÕES, DISPUTAS E ESPERANÇAS. UMA ALTERNATIVA AO CAPITALISMO}

\author{
Ramiro Avila Santamaría*
}

Resumen: En este ensayo, por varias razones, nos centraremos en una de las más importantes propuestas indígenas al constitucionalismo transformador contemporáneo el sumak kawsay - bién como sus contradiciones, disputas e esperanzas, a partir de un análisis de apropiación del sumak kawsay por el Estado ecuatoriano y por la noción de desarrollo capitalista de ese mismo Estado. Se utilizará la situación del Yasuní, como estudio de caso, para observar las contradicciones del sistema capitalista y las potencialidades del sumak kawsay. El Yasuní es un territorio concreto donde se experimentan violencias y resistencias, razones para el pesimismo y para la esperanza.

Palabras-llave: Sumak Kawsay; Nuevo Constitucionalismo; Capitalismo, Desarollo; Yasuní.

Resumo: Neste ensaio, por várias razões, nos centraremos em uma das mais importantes propostas indígena ao constitucionalismo transformador contemporâneo o sumak kawsay - bem como suas contradições, disputas e esperanças, a partir de uma análise de apropriação do sumak kawsay pelo Estado equatoriano e pela noção de desenvolvimento capitalista desse mesmo Estado. Se utilizará da situação de Yasuní, como estudo de caso, para observar as contradições do sistema capitalista e as potencialidades do sumak kawsay. O Yasuní é um território concreto onde há violências e resistências, razões para o pessimismo e para a esperança.

Palavras-chave: Sumak Kawsay; Novo Constitucionalismo; Capitalismo, Desenvolvimento; Yasuní.

\section{INTRODUCIÓN}

En el año 1990 por primera vez en Ecuador se sentaron en la misma mesa, en igualdad de condiciones, un presidente de la república con líderes indígenas. El 28 de mayo de 1990, después de un largo y complejo proceso organizativo (LLASAG, 2013, p. 123), un grupo de indígenas se tomaron la iglesia de Santo Domingo en Quito y, al mismo tiempo, el movimiento indígena paralizó el país. Ante la absorta mirada de los

\footnotetext{
* Abogado por la Pontificia Universidad Católica del Ecuador (PUCE), Master en Derecho por Columbia University (New York), Master en Sociología Jurídica por la Universidad del País Vasco-Instituto Internacional de Sociología Jurídica. Doctor en Sociología Jurídica (candidato) por la Universidad del País Vasco. Docente de planta del Área de Derecho de la Universidad Andina Simón Bolívar-Sede Ecuador y coordina la Maestría en Derecho Penal. Es autor y editor de varias publicaciones, entre ellas: En defensa del neoconstitucionalismo andino (Quito 2014), La (in)justicia penal en la democracia constitucional de derechos (Quito 2013), Neoconstitucionalismo transformador (Quito 2011), Derechos y garantías.Ensayos críticos (Quito 2010).E-mails: ramiro.avila@uasb.edu.ec, ravila67@gmail.com
} 
El Sumak Kawsay y el Yasuní: contradicciones, disputas y esperanzas. Una alternativa al capitalismo

mestizos, los indígenas hicieron escuchar su voz. Los indígenas criticaban al sistema capitalista y proponían otro modelo de organización social y política.

Han pasado 25 años desde aquel histórico levantamiento en el que el movimiento indígena se convirtió en un actor político protagónico y sus luchas tienen resonancia jurídica y política. Ecuador, después de 1990, no es el mismo. Desde 1990 hemos tenido una tensión que va entre el escuchar la voz de los indígenas y, al mismo tiempo, de silenciarla. El Estado ha reconocido muchas de sus demandas a nivel jurídico. En el 2008 se plasmaron a nivel constitucional múltiples propuestas que vinieron desde el movimiento indígena: el estado plurinacional, la interculturalidad, la justicia indígena, la democracia comunitaria, la pachamama (derechos de la naturaleza) y el sumak kawsay. En este ensayo, por varias razones, nos centraremos en una de las más importantes propuestas indígenas al constitucionalismo transformador contemporáneo: el sumak kawsay. El sumak kawsay es "una de las ventanas privilegiadas para analizar las contradicciones, las ambivalencias, los ritmos, los avances y los retrocesos de los procesos de transformación social", y porque ha sido una reivindicación indígena que "desafía todo el edificio jurídico y político del Estado moderno colonial" (SANTOS, 2013, p. 14).

Este ensayo está dividido en tres partes. En la primera se describe al capitalismo como forma de organización socio-económica hegemónica. En esta parte se afirma que el capitalismo intrínsecamente requiere inequidad, violencia, extractivismo, destrucción y muerte. Al final de esta parte se concluye que es urgente salir de esta forma de organización y buscar alternativas. En la segunda parte se describirá una de las alternativas al capitalismo, que es el sumak kawsay. El sumak kawsay es una institución constitucional en Ecuador y Bolivia que está en disputa. Se describirá las principales perspectivas y la visión que asumimos, que es un sistema de vida y una forma de organización social que recoge tanto el saber indígena como los saberes emancipatorios de occidente. Para explicar al sumak kawsay se utilizará, además de doctrina contemporánea, la literatura con el objeto de hacer un ejercicio de ecología de saberes (SANTOS, 2010, 58). Finalmente, se explica la situación del Yasuní, como estudio de caso, en donde se pueden observar las contradicciones del sistema capitalista y las potencialidades del sumak kawsay. El Yasuní es un territorio concreto donde se experimentan violencias y resistencias, razones para el pesimismo y para la esperanza. 


\section{EL CAPITALISMO: UN SISTEMA DE INEQUIDAD Y MUERTE}

Nuestro pueblo y nuestra selva valen más que todas las petroleras del mundo y sus magnates juntos. Nos hablan de una globalización que nos quiere desechar por el hecho de que no hablamos el lenguaje del dinero y el mercado.

Comunidad indígena Sarayaku, Sarayaku, El libro de la vida de Sarayaku para defender nuestro futuro, 82

Mister Taylor sale de Boston sin un centavo y aparece en América del Sur, en la región del Amazonas. Convive con los indígenas de una tribu. Por su aspecto, le llamaban el gringo pobre. Un día, en busca de hierbas para alimentarse, se internó en la selva. Por pura casualidad se encontró con un nativo. Éste le dijo: buy head? Money, money. Le ofrecía una cabeza reducida. Como no tenía dinero, Mister Taylor aparentó no comprender. "El indio se sintió terriblemente disminuido por no hablar bien inglés, y se la regaló pidiendo disculpas" (MONTERROSO, 1998, p. 10). Mr. Taylor, hombre de vasta cultura, entregado a la contemplación, contaba uno por uno los pelos de la cara. Aburrido, dispuso obsequiar la cabeza a un tío suyo, Mr. Rolston, "quien desde la más tierna infancia había revelado una fuerte inclinación por las manifestaciones culturales de los pueblos hispanoamericanos" (MONTERROSO, 1998, p. 11).

Mr. Rolston pide 5 cabezas. Luego, solicita 10 cabezas. Un mes más tarde, 20. Mr. Taylor presintió que se trataba de un negocio y así lo confirmó. Se conformó una sociedad mercantil. El uno adquiere las cabezas y el otro las vende. Mr. Taylor consiguió permiso de exportación y una concesión exclusiva por 99 años. Este sería un "paso patriótico que enriquecería en corto tiempo a la comunidad" (MONTERROSO, 1998, p. 12). A cambio, los aborígenes, en la pausa de recolección de cabezas, recibirían un refresco bien frío, "cuya fórmula mágica él mismo proporcionaría" (MONTERROSO, 1998, p. 12). El parlamento, cuando se dieron cuenta de las ventajas, promulgaron un decreto "exigiendo al pueblo que acelerara la producción de cabezas reducidas" (MONTERROSO, 1998, p. 12).

Meses más tarde, en Estados Unidos, las cabezas alcanzaban popularidad. Al principio era privilegio de familias pudientes. Luego se fue popularizando. Todo hogar tenía su cabeza; si no la tenía, se consideraba hogar fracasado. Hubo 
El Sumak Kawsay y el Yasuní: contradicciones, disputas y esperanzas. Una alternativa al capitalismo

coleccionistas y otros que compraban cabezas raras para salvarse de la vulgaridad. Hubo inversión extranjera "para impulsar el desenvolvimiento de aquella manifestación cultural" (MONTERROSO, 1998, p. 13). Efectivamente, "la tribu había progresado en tal forma que ya contaba con una veredita" (MONTERROSO, 1998, p. 13).

Pero vino la escasez. Las meras defunciones resultaron insuficientes. ¿Cómo elevar la mortalidad a "un nivel grato a los intereses de la Compañía"? Había que "tomar medidas heróicas." Se estableció la pena de muerte. "Los juristas se consultaron unos a otros y elevaron a la categoría de delito hasta la falta más nimia" (MONTERROSO, 1998, p. 14). Si alguien se quejaba de mucho calor y se comprobaba que no era para tanto, o si estornudaba sin justificación, le ejecutaban enseguida. La cabeza para la compañía, el resto para los familiares. Se estableció una legislación sobre las enfermedades. Los enfermos graves debían morirse en 24 horas, salvo si contagiaban a la familia. Las víctimas de enfermedades leves eran despreciadas y escupidas en la cara. Fallecer y no curar eran actos patrióticos. Hubo un período de auge económico. Industrias subsidiarias, como las de ataúdes, florecieron. Se construyó otra veredita. Por su parte, Mr. Taylor fue consejero particular del Presidente. Poca gente quedaba en el pueblo: las autoridades y periodistas, y sus señoras.

El progreso exigía el único remedio posible: fomentar la guerra entre tribus vecinas. Las tribus fueron eliminándose. Una, dos, tres, cuatro y cinco tribus. "El progreso se extendió con tanta rapidez que llegó la hora en que, por más esfuerzos que realizaron los técnicos, no fue posible encontrar tribus vecinas a quienes hacer la guerra” (MONTERROSO, 1998, p. 16). Todo comenzó a languidecer. La gente "estaba más triste y fúnebre que nunca" (MONTERROSO, 1998, p. 17).

Y todos sentían como si acabaran de recordar de un grato sueño, de ese sueño formidable en que tú te encuentras una bolsa repleta de monedas de oro y la pones debajo de la almohada y sigues durmiendo y al día siguiente temprano, al despertar, la buscas y te hallas con el vacío (MONTERROSO, 1998, p. 17).

Se dormía con dificultad y con temor a "amanecer exportado". Todos exigían, en el país de Mr. Taylor, cabecitas hispanoamericanas. Se pedía más y más. Los embarques disminuyeron uno por mes "ya con cualquier cosa, con cabezas de niño, de señoras, de diputados." 
De repente cesaron del todo. Un viernes áspero y gris, Rolston saltó de la ventana cuando al abrir un paquete de correo encontró la cabecita de Mr. Taylor, que parecía decirle desde el fiero Amazonas: "perdón, perdón, no lo vuelvo a hacer" (MONTERROSO, 1998, p. 18).

La historia de Mr. Taylor es la historia del capitalismo y de la relación entre países hegemónicos y periféricos. En un inicio, Mr. Taylor sale del primer mundo sin un centavo y se dirige a América del Sur. Mr. Taylor podría ser el mismo Cristóbal Colón, o cualquier otro aventurero que ha buscado suerte y mejor vida en el Sur. El encuentro con el mundo indígena es un desencuentro, un hecho no esperado y hasta cierto punto indeseado. Mr. Taylor simplemente quería comer y estaba sobreviviendo. Aparece un indígena y ambos se asustan. El uno le ofrece una cabeza reducida, tzantza, y el otro no tenía más que demostrar incomprensión. Para el indígena, la tzantza tiene un valor cultural enorme. De hecho, es una especie de trofeo de guerra. Para Mr. Taylor no es nada y lo único que le llama la atención son los pelos de la cara. En ese encuentro, existe ya una relación asimétrica: el indio se siente disminuido, cree que hizo algo inadecuado y acaba regalando la cabeza. La distancia entre el indígena y el norteamericano culturalmente se irá alejando de forma proporcionalmente inversa a la relación comercial que se irá creando.

Mr. Taylor envía la cabeza a su tío Mr. Rolston, y éste encontrará el valor de cambio de la tzantza. La cabeza reducida se convierte en un recurso natural. La cabeza podría ser cacao, oro, caucho, plata, canela, cobre, banano, petróleo. Pero la metáfora va al extremo: se trata de un objeto que solo puede provenir de un cuerpo humano. Las tzantzas entran al mercado, tienen precio, se pueden vender y comprar. El símbolo de guerra se convierte en un adorno exótico. ¿Cómo era la vida de cada una de las cabezas? ¿Qué pensaban, qué necesidades tenían, qué luchas libraban, qué podían enseñar, tenían nombres, papás, hijas, hizo algo bueno en la vida? No importa. El objeto de comercio tiene que ser descontextualizado, sin historia, sin cultura, sin vida. En la relación asimétrica solo importa el significado que otorga el que tiene el dinero. ¿Tiene sentido preguntar cuánto ganaba y si iba a la escuela el niño que coció los botones de nuestra camisa fabricada en Filipinas?

La iniciativa del comercio viene del Norte. Hay que importar con exclusividad y garantizar la mayor ganancia posible. Varios mecanismos garantizan este lucrativo negocio: un tratado de libre comercio, propiedad intelectual, leyes que protejan la propiedad, promuevan la inversión y la ganancia, intercambio desigual (los R. Fac. Dir. UFG, v. 41, n.1, p. 166-197, jan. / jun. 2017 
El Sumak Kawsay y el Yasuní: contradicciones, disputas y esperanzas. Una alternativa al capitalismo

indígenas entregan sus cabezas y a cambio reciben un refresco), estado protector y todo el pueblo colaborando y sacrificándose para que el negocio no se detenga. Desde el lado del consumo, se creó la necesidad, la exclusividad, la moda: todo hogar tenía su cabeza. Desde el lado del productor, había "progreso": la veredita y mucha violencia.

Si la explotación de cabezas significaba que tarde o temprano la cabeza de todos los indígenas sería reducida, ¿cómo se explica que la gente colabore con la empresa transnacional? Acá es donde entra la ideología y viene el discurso del desarrollo. El desarrollo es una

construcción intelectual destinada a justificar y promover la expansión de un modelo y unos valores - los occidentales - como necesario revulsivo para superar el supuesto atraso de sociedades caracterizadas por otras referencias culturales y otras formas de organización social y de relación con la naturaleza (UNCETA, 2014, p. 67).

El libre comercio de cabezas reducidas es "paso patriótico que enriquecería en corto tiempo a la comunidad". Beneficia a la nación, enriquece a la gente, trae progreso. Y el desarrollo exige sacrificio y mucho heroísmo. Satisfacer el mercado significa producir más que lo necesario y esto implica agotar los recursos naturales. Morir, matar, hacer la guerra era un virtud siempre que sirva para atender el mercado del primer mundo. Como afirma Galeano, "nuestra derrota siempre estuvo implícita en la victoria ajena; nuestra riqueza ha generado siempre nuestra pobreza para alimentar la prosperidad de otros" (2004, p. 16). Conseguir la mercancía y el progreso se lo hace a cualquier costo. El costo es la vida misma tanto del vendedor como del comprador. Por eso Llasag afirma que "la utilización del término desarrollo es contrario al sumak kawsay como sistema de vida" (2009, p. 121). El cuento nos abre la posibilidad de mirar el daño no solo desde el lado del abastecedor de materia prima sino también del comerciante y del consumidor. Mr. Taylor, quien se enriqueció con el negocio, acaba también triturado por la máquina del mercado. Mr. Rolston, muy tarde, se da cuenta que también a él le llegará la hora de morir y se mata.

El capitalismo tiene una fascinación por la muerte, y no solo por la muerte física y cultural, sino por los objetos muertos. A este fenómeno Esterman lo denomina "Necrofilia del androcentrismo." El capitalismo idolatra objetos muertos, como las tzantzas, los automóviles, las computadoras, los aviones. También se refleja el "amor" a los objetos muertos cuando optamos por reemplazar los procesos orgánicos por 
mecánicos, y ahí podemos verificar en la biomedicina, la robótica, la manipulación genética, la sexualidad por el cibersexo, la afectividad por el consumo de bienes, el origen de la vida en lugar de encuentro de pareja por fecundación in vitro (ESTERMAN, 2014, p. 54). La muerte nos lleva a un axioma suicida: si Mr. Taylor vive, los indígenas no viven; si Mr. Rolston vive, Mr. Taylor tiene que morir. La relación trágica entre Caín y Abel se reproduce cotidianamente: si yo vivo, tú no vives, y su tú vives, yo no vivo (MONTERROSO, 1998, p. 58). El varón lo conquista todo, en el mundo de la economía, en el deporte, en la bolsa de valores, en la relación de pareja.

El drama de Mr. Taylor ha sido el drama de todos los pueblos de América Latina de la periferia. Mr. Taylor y Mr. Rolston son Hernán Cortés, Pedro de Alvarado, Francisco de Orellana, Gonzalo Pizarro, las misiones del Fondo Monetario Internacional, los directivos del Banco Mundial, los ejecutivos de las empresas transnacionales. La primera tzantza fueron los metales preciosos, el oro y la plata, que era el medio de pago para el tráfico comercial, y que "impulsó la travesía de los mares malditos. Europa entera necesitaba plata" (GALEANO, 2004, p. 28). Años más tarde, lo mismo pasó con el cacao en Venezuela, el café en Colombia, Ecuador, Brasil y los países centroamericanos. "Cuanto más codiciado por el mercado mundial, mayor es la desgracia que un producto trae consigo al pueblo latinoamericano" (GALEANO, 2004, p. 85). En nuestro siglo, lo mismo sucede con el petróleo, la minería y productos como la cocaína. "Una vez más, se optaría por la explotación de los recursos naturales por las necesidades externas y no por razones nacionales" (ACOSTA, 2009, p. 39). Acosta sostiene que en toda explotación intensiva de "recursos naturales" se produce el "efecto voracidad": desesperada búsqueda y apropiación abusiva de los excedentes generados por el sector exportador, deterioro irreversible del medio ambiente natural y social, lucha por el excedente, concentración de riqueza y poder político en pocas manos (ACOSTA, 2009, p. 158). Cada país de la periferia nos hemos especializado en exportar algún "recurso natural". El resultado siempre es el mismo: pocos acumulan riqueza, explotación, mucho dolor, violencia y exclusión. En las Américas, antes de la conquista, se calcula que existían setenta millones de personas, un siglo y medio después se redujo a tres millones y medio (GALEANO, 2004, p. 59). ¿Cómo se llama este sistema que produce historias como las de Mr. Taylor y de cualquier país de la periferia? Pues estamos hablando del sistema capitalista.

Ante la ideología del desarrollo, tenemos tres opciones. La una es seguir usando el concepto, apostar a la misma fórmula de aumentar el pastel para después R. Fac. Dir. UFG, v. 41, n.1, p. 166-197, jan. / jun. 2017 
El Sumak Kawsay y el Yasuní: contradicciones, disputas y esperanzas. Una alternativa al capitalismo

repartirlo, sin alterar el marco metodológico. La otra salida es promover el desarrollo humano y sustentable, que mejore las condiciones y capacidades de la gente y sea amigable con el medio ambiente. La tercera alternativa, la más radical, que es una utopía que necesitamos tanto como la boca necesita el pan (SANTOS, 2006, p. 46), es negar el desarrollo. En esta última alternativa ubicamos al sumak kawsay.

\section{EL SUMAK KAWSAY COMO MODELO ALTERNATIVO AL DESARROLLO}

NOSOTRAS Y NOSOTROS, el pueblo soberano del Ecuador

Decidimos construir

Una nueva forma de convivencia ciudadana,

En diversidad y armonía con la naturaleza,

Para alcanzar el buen vivir, el sumak kawsay

Preámbulo, Constitución de Ecuador, 2008

El Estado asume y promueve

Como principios ético-morales de la sociedad plural:

Suma qamaña (vivir bien)

Art. 8.I, Constitución de Bolivia, 2009

El sumak kawsay es una expresión kichwa que significa "vivir a plenitud."

En la Constitución de Ecuador del año 2008 se reconoció como "buen vivir" y en la boliviana como "vivir bien." Este reconocimiento ha sido considerado por muchos juristas y cientistas sociales como un hito histórico. "Es la primera ver que una noción que expresa una práctica de convivencia ancestral respetuosa con la naturaleza, con las sociedades y con los seres humanos, cobra carta de naturalización en el debate político y se inscribe con fuerza en el horizonte de las posibilidades humanas" (DÁVALOS, 2014, p. 142). Desde Bolivia se ha considerado que suma qamaña "sintetiza el nuevo estilo de país que deseamos construir" y que es la plasmación de la utopía del país presente en la Constitución Boliviana (ALBÓ, 2009, p. 1). Pero ¿cómo entenderlo?¿Cuál es su aporte a los problemas y contradicciones creadas por el sistema capitalista? ¿Contribuye el sumak kawsay a la construcción de una utopía constitucional andina? Las respuestas a estar preguntas no son fáciles ni unívocas. El mundo andino es diverso y la pluralidad de perspectivas se refleja en el debate sobre el sumak kawsay. 


\title{
3.1 La comprensión y las disputas sobre el sumak kawsay
}

Al mirar las publicaciones sobre el sumak kawsay podemos afirmar que hay distintas perspectivas, múltiples voces, no hay consensos sobre su contenido y alcance, y hay una evidente disputa sobre su comprensión. Estas disputas sobre el sumak kawsay podrían ubicarse en una de estas tres corrientes: (1) desarrollista-estatista, (2) indigenista-pachamamista, y (3) ecologista-post desarrollista (HIDALGO; CUBILLO, 2014b, p. 27).

(1) En la visión desarrollista-estatista, el sumak kawsay es el objetivo central de la política pública, que se define y materializa en el Plan Nacional del Buen Vivir 2013-2017 (PNBV). De acuerdo con el plan,

\begin{abstract}
El Sumak Kawsay fortalece la cohesión social, los valores comunitarios y la participación activa de individuos y colectividades en las decisiones relevantes, para la construcción de su propio destino y felicidad. Se fundamenta en la equidad con respeto a la diversidad, cuya realización plena no puede exceder los límites de los ecosistemas que la han originado. No se trata de volver a un pasado idealizado, sino de encarar los problemas de las sociedades contemporáneas con responsabilidad histórica (SENPLADES, 2013, p. 21).
\end{abstract}

Esta concepción sobre el "buen vivir" elaborado por la Secretaría de Planificación, parecería que no es compartida ni se nutre del saber popular, y estas visiones están lejos de ser parte del sentir del pueblo ecuatoriano, tanto de mestizos como de poblaciones indígenas o afrodescendientes. En uno de los videos que se pueden encontrar en la página oficial de la secretaría de planificación del gobierno ecuatoriano, que se denomina ¿qué es el buen vivir? (SENPLADES, 2013), se puede apreciar la impresionante cantidad de voces que reflejan la diversidad ecuatoriana, pero al mismo tiempo la distancia abismal entre lo que hemos transcrito y lo que dice la gente cuando se le pregunta sobre el concepto de "buen vivir": recuperar la humanidad, vivir en paz con uno mismo, portarse bien con los amigos, tener una vivienda propia, es lindo, jugar, la amistad, hacer deporte, cumplir mis metas, gozar la naturaleza, no hacer un humo en los carros, tener salud, tener ánimo, vivir feliz con mis padres, no pelear, compartir ideas, visitar padres, jugar con primos, convivir en armonía.

El PNBV reconoce que la noción ha estado presente en los pueblos originarios y que recogió los planteamientos de los pueblos andino-amazónicos (p. 23), 
El Sumak Kawsay y el Yasuní: contradicciones, disputas y esperanzas. Una alternativa al capitalismo

también reconoce a la naturaleza como sujeto de derechos (p. 16, 17, 24, 36, 37, 69, 73, $81,82,172,193,221,222,233$ ), que hay que vivir en armonía con la naturaleza (p. 23, 24, 25, 26, 160), y que merece respeto y protección (p. 33, 128, 170, 173, 223, 235, 266, $322,346)$. Incluso admite que la naturaleza es "evaluada a partir de un marco legal obsoleto, bajo una concepción que la categoriza como un recurso y que responde a consideraciones utilitarias de explotación de los recursos naturales, y no a las de la actual enfoque que plantea la Constitución" (p. 223). Sin embargo, en el PNBV el gobierno ecuatoriano considera a la naturaleza como recurso natural que es administrado por el Estado, "la inversión pública es una variable clave para lograr el crecimiento económico", el éxito económico se mide en la reducción de la pobreza medida en ingreso de dinero (p. 15) y la equidad es un imperativo para erradicar la pobreza (p. 18). También afirma que el buen vivir es una idea "que va más allá del concepto de desarrollo, pues está asociado a una noción más amplia de progreso."

Cuando el PNBV aborda el tema del crecimiento económico, enuncia tres defectos: la falta de distribución, la falta de mejora de la calidad de vida y la falta de sostenibilidad (p. 22). Es decir, el problema no es el crecimiento económico, que el PNBV buscará con la explotación intensiva de los "recursos naturales", sino los defectos en sus logros. Cuando habla de la naturaleza, la preocupación es "minimizar los impactos ambientales y sociales de sus actividades productivas e industriales" (p. 26). El capitalismo aparece como un problema, como un paradigma distinto al del "buen vivir", se le atribuye una lógica excluyente e inequitativa que lo sustenta (p. 45), que produce desigualdad y pobreza (p. 81). Sin embargo, hay categorías propiamente capitalistas que no se cuestionan, como crecimiento económico, progreso que hay que potenciar para superar la crisis del capitalismo global (p. 256), y la noción misma de desarrollo, que es el nombre del plan, en la que distingue visiones convencionales: el desarrollo humano (p. 27, 28, 62, 120), el desarrollo sustentable (p. 29, 240, 251), y el desarrollo como progreso, crecimiento y como incremento de la producción y explotación de "recursos naturales." ${ }^{1}$ La consideración de la naturaleza como "recurso natural", como objeto de apropiación, uso y disposición de parte del Estado, y como elementos aislados, la encontramos a lo largo del documento. ${ }^{2}$ El fin de la explotación de recursos es generar riqueza, acumular, invertir (p. 304) y permitir el desarrollo de las fuerzas productivas (p. 339). 
Rafael Domínguez y Sara Caria, en un interesante ensayo que analiza el PNBV a la luz de la ideología, concluye que el buen vivir para el Estado y el gobierno "es una ideología funcional para el modelo de desarrollo primario exportador (antitético a los principios del BV)" (2014, p. 1)", y que utiliza la noción para ocultar realidades innombrables, como la falta de distribución de tierras (el 52\% de tierras agrícolas pertenecer a un $5 \%$ de propietarios) y la protección de grandes terratenientes (p. 28), para generar una ilusión movilizadora que simplifica la realidad y elude la responsabilidad de reorganizar la sociedad y el estado (p. 36), y para reforzar una ideología dominante encaminada a implementar un proyecto de modernización capitalista (p. 44).

La esquizofrenia del PNBV no es original ni única, también la encontramos en la misma Constitución de Montecristi. Por un lado, la naturaleza aparece como sujeto de derechos, ${ }^{3}$ con la que el ser humano debe vivir en armonía ${ }^{4}$, y a la que las personas y el Estado deben respeto y protecció. ${ }^{5}$ Enunciados que, como veremos, están estrechamente relacionados con el sumak kawsay. Sin embargo, la Constitución reconoce al desarrollo como el régimen económico (Art. 275), y que es un deber primordial del estado (Art. 3). Encontramos las variantes del desarrollo: desarrollo humano (Art. 59), desarrollo socioeconómico (Art. 249), desarrollo sustentable (Art. 259). La naturaleza es un "recurso natural" que pertenece al Estado de forma inalienable e imprescriptible (Arts. 1, 317), considerada de forma individual y aislada, ${ }^{6}$ y que debe ser explotada. ${ }^{7}$ Por otro lado, la Constitución, en la clasificación de los derechos, evita la división tradicional por generaciones, que han generado críticas por la distorsión en cuanto a la evolución histórica (visión occidental) y por la jerarquización de unos derechos sobre otros (PISARELLO, 2007, 19 y 79), pero denomina a los derechos económicos, sociales y culturales (DESC) como "derechos del buen vivir." Esta denominación puede llevar a tergiversaciones inadecuadas. En primer lugar, por el principio de relacionalidad, el sumak kawsay implicaría la vivencia armónica de la gran mayoría de derechos y no solo los DESC; en segundo lugar, el sumak kawsay no puede disociarse de la Pachamama, que según la constitución pertenecen a otro agrupamiento de derechos; en tercer lugar, la categoría "derechos del buen vivir", "desnaturaliza el verdadero sentido del sumak kawsay, lo cual conlleva a confundir o pensar que los derechos sociales equivalen a derechos del buen vivir" (LLASAG, 2009, p. 124). Se podría afirmar que esta lectura reduccionista no es la adecuada y hay que mirar a los derechos del buen vivir en el contexto de la Constitución, sin embargo las R. Fac. Dir. UFG, v. 41, n.1, p. 166-197, jan. / jun. 2017 
El Sumak Kawsay y el Yasuní: contradicciones, disputas y esperanzas. Una alternativa al capitalismo

interpretaciones restrictivas existen y el PNBV es la demostración. Algo parecido sucede con la Constitución de Bolivia, en la que aparecen el suma qamaña en aymara junto con "largas glosas de conceptos más occidentales", como la noción de medio ambiente, calidad de vida, sustentabilidad, seguridad jurídica, interés individual, eliminación de pobreza, "desarrollo productivo industrializador de los recursos naturales" ${ }^{\prime}$, aparato productivo, autonomía campesina, en los que omite referencias específicas a valores centrales del concepto suma qamaña (ALBÓ, 2009, p. 10).

Estas tensiones entre naturaleza como sujeto de derechos o como recurso natural, sumak kawsay o desarrollo, los derechos del buen vivir como DESC y la visión holística del sumak kawsay, han sido resueltas por parte del Estado a favor de la consideración hegemónica y tradicional como recurso y por el desarrollo. Los derechos y el sumak kawsay son mera retórica. Por ello, Unceta ha considerado que el uso del sumak kawsay se trata de un "intento de hibridación, queriendo mezclar dos matrices de pensamiento difícilmente compatibles", y que se trata de una comprensión desarrollista en sentido convencional del término, light e irrelevante (2014, p. 134-135). Por su parte, Gudynas considera que el uso del sumak kawsay por el gobierno se trata de una "activa apropiación o secuestro de las ideas originales del Buen Vivir, para redefinirlas desde una racionalidad gubernamental y hacerlas funcionales al desarrollo convencional" (2014, p. 31). En la construcción estatal, afirma Dávalos, y en el uso del término, se trata de una propuesta tecnocrática, sin participación popular ni indígena, sin diálogo ni debate, que intentan convertir al sumak kawsay en una nueva variante de etnodesarrollo, con el objeto de reforzar mecanismos de colonización y acumulación de capital (2014, p. 258). En suma, la visión plasmada en una parte de la Constitución y en la gran mayoría del PNBV se quedan dentro de la modernidad capitalista. Desde esta concepción, el sumak kawsay se suma a una noción ya bautizada y a un paradigma atropocéntrico y mecanista (MEDINA, 2014, p. 135).

(2) La segunda concepción es la que se ha venido conociendo como "Pachamamista", que es considerada como la genuina indigenista (HIDALGO, 2014, p. 35). Oviedo considera que la concepción ancestral andino es la "única fuente de la que se puede enteder a este sistema de vida y conciencia" (2014b, p. 276), y que no tiene relación alguna con la noción del buen vivir esbozada por el gobierno ni las derivadas del buen vivir aristotélico. 
Pretender hablar del sumak kawsay sin conocer la cosmociencia andina es la práctica arribista, enajanante y estereotipada de siempre. Uno no puede conocer realmente el pensamiento filosófico de un pueblo si nunca se ha sentado a su mesa, sino ha bailado sus danzas, sino ha sufrido con él (OVIEDO, 2014b, p. 294).

La propuesta viene del mundo indígena y los pueblos de ese mundo son los sujetos autorizados para definir su contenido y alcance (PACARI, 2014, p. 345), que es un saber milenario acumulado (OVIEDO, 2014, p. 340), que comienza a manifestarse en las reivindicaciones indígenas cuando se conmemoró los 500 años de descubrimiento de América y se escuchó el punto de vista de las víctimas (CRESPO, 2013, p. 56). Discursos como estos nos dan una idea de su cosmovisión:

\begin{abstract}
En nuestros lugares sagrados y templos, wakas y pukaras, que nosotros tenemos en espacios como las cascadas, el rio, la selva (sacha), o la montaña (urku). Es decir, todos estos lugares juegan un papel dentro de la visión de los pueblos indígenas, y en dicha visión estos lugares tienen vida. Para nosotros todo tiene vida; a través de la energía, que es el espíritu, sea de la piedra o del río, éstos nos anuncia o nos hablan. Por lo mismo diríamos nosotros que el río o las aguas son vida, están ligadas a la sacralidad, y nos purifican. Y la comprensión que tenemos es que, si estamos conscientes de que el ser humano está compuesto en su organismo por un $80 \%$ de líquido, tiene un sentido del por qué es vida; y por qué la concepción de lo sagrado y por qué el agua se utiliza para purificación, la sanación (PACARI, 2014, p. 346).
\end{abstract}

Esterman es de los pensadores que sostienen que la fuente para la comprensión del sumak kawsay es la filosofía andina. En esta línea, hay que ser fieles a los aportes históricos de los pueblos indígenas (CHANCOSA, 2014, p. 210) y hay que entender que "el sumak kawsay es la voz de los pueblos quechuas para el Buen Vivir" (DÁVALOS, 2014, p. 149).

La visión de un mundo indígena que vive en armonía con la naturaleza, que ha permanecido en el tiempo y ha resistido a la civilización, ha sido fuertemente criticada. Sánchez Parga sostiene que

creer que los esquemas del pasado pueden servir para pensar y cambiar las realidades actuales es una evasión mental, no son más que un recurso ideológico e interpelativo de movilizaciones imaginarias. El recurso a discursividades étnicas (pachamama, sumak kawsay) es portador de una utopía reaccionaria, que adopta el pasado como proyecto de futuro (2011, p. 31). 
El Sumak Kawsay y el Yasuní: contradicciones, disputas y esperanzas. Una alternativa al capitalismo

Más aún, esta concepción del mundo no existe, es inventada, que solo sirve como justificación y como ideología actual. También se ha dicho que esta visión es romántica, idealizada, que habla de pueblos y de cosmovisiones indígenas "como si estas hubieses permanecido sin grandes modificaciones a lo largo de los siglos y como si estas fueren iguales en todas las etnias y regiones" (MANCILLA, 2011, p. 95).

Hay unos datos mencionados por Gudynas sobre una encuesta realizada en Bolivia, que pueden ayudar a entender lo difícil de esta entrada "pachamamista" y de alguna manera confirman las afirmaciones de sus críticos. La población indígena encuestada considera en un $85 \%$ que el "buen vivir" es bienestar material, un $70 \%$ lo asocia con desarrollo y progreso, y apenas un 7\% lo relaciona con valores espirituales y comunitarios (2014, p. 41). La visión de Pacari, en otras palabras, no es compartida por más del 93\% de indígenas bolivianos. Por ello, al decir de Mancilla, es dudoso que las palabras de ciertos líderes indígenas represente el sentir y pensar de las comunidades indígenas y lo más probable es que reproduzca opiniones de expertos urbanos (MANCILLA, 2011, p. 102).

Por otro lado, una visión indígena purista atentaría con algunos principios básicos del sumak kawsay, tales como la interrelación y la interdependencia, y de una democracia participativa, que es la igual valoración de las personas y las culturas de quienes deberían intervenir. Si sólo las poblaciones indígenas pueden comprender y tener voz para comprender el sumak kawsay, entonces esas culturas serían superiores y mejores. En donde una cultura prevalece, sea esta la hegemónica occidental o una indígena, no puede existir una auténtica interculturalidad.

No existe, pues, una visión unívoca y una verdad absoluta. Debemos, como hace el llamado Unceta, huir de posiciones ingenuas, que no toman en cuenta globalización y diversidad, y de las simplificaciones (UNCETA, 2011, p. 114). Para evitar frustración, debemos intentar tener rigor y redoblar esfuerzos de reflexión crítica. El sumak kawsay es una oportunidad para el diálogo y para el encuentro. En esta tónica, la tercera corriente parecería la más adecuada para encontrar salidas al desarrollo de la modernidad capitalista.

(3) La tercera concepción, que es una crítica radical al concepto de desarrollo y propone un alternativa fuera del capitalismo, no desprecia las experiencias ni las teorías emancipatorias, vengan de donde vengan, y, por supuesto, considera los 
valores, las prácticas y las ideas de las comunidades indígenas que han resistido a la colonialidad. En palabras de quien fuera uno de los impulsores del término en el texto constitucional, "el Buen Vivir es un proyecto que, al haber sumado muchas historias de luchas de resistencia y de propuestas de cambio, al nutrirse de experiencias nacionales e internacionales, se posiciona como punto de partida para construir democráticamente sociedades democráticas" (ACOSTA, 2012, p. 25). La idea de la construcción de forma democrática y en conjunto, y del origen indígena, lo confirma Nina Pacari:

\begin{abstract}
Nuestras organizaciones en las asambleas, en tiempos de la Constituyente de 2008, dijeron: este es el tiempo para colocar el paradigma del sumak kawsay, si no colocamos ahora estaremos esperando otros veinte años. Por lo tanto ahora ya están los dos pies para poder caminar: por un lado, el Estado plurinacional, que alude a toda la estructura o superestructura, la toma de decisiones, el ejercicio de poder horizontal, la democratización; $\mathrm{y}$, por otro lado, el nuevo orden económico, la equidad, la justicia, el compartir, la solidaridad; y eso hay que construirlo en conjunto (PACARI, 2014, p. 354).
\end{abstract}

En esta línea, la lidereza indígena Chancosa afirma que "el sumak kawsay es una práctica social de los pueblos indígenas; es un proyecto societal indígena en permanente construcción, abierta a otros aportes, en el que quepan todas las entidades históricas y sociales comprometidas con la construcción de una nueva sociedad. El sumak kawsay no es un proceso cerrado, exclusivista; no puede serlo porque se sostiene en principios de inclusión y equidad." (2014, p. 209).

Alberto Acosta sostiene que el sumak kawsay "plantea una cosmovisión diferente a la occidental al surgir de raíces comunitarias no capitalistas" (2011, p. 51), que recupera saberes y culturas indígenas, pero al mismo tiempo "forma parte de una larga búsqueda de alternativas de vida fraguadas al calor de las luchas de la Humanidad, por la emancipación y la vida" (2011, p. 53). Por un lado, el sumak kawsay se nutre de los saberes y prácticas ancestrales (HOUTART, 2011, p. 57), y por otro,

su mayor contribución podría estar en la construcción colectiva de puentes entre los conocimientos ancestrales y modernos. Tal vez el diálogo consista en que los del pasado miren algo más al futuro (y al presente) y los del futuro aporten una visión menos beata del pasado (ACOSTA 2011, p. 55). 
El Sumak Kawsay y el Yasuní: contradicciones, disputas y esperanzas. Una alternativa al capitalismo

A esta práctica que fusiona tanto saberes y prácticas, aportes indígenas y occidentales, Esterman la llama hermenéutica politópica "que incluye el punto de vista del otro y de la otra, la participación de más que dos tradiciones culturales o civilizacionales en el polílogo intercultural. Incluyendo en las reflexiones también al otro y la otra no-humanos, es decir alteridad esófica" (2014, p. 51).

La propuesta es explorar saberes indígenas y también propuestas teóricas emancipatorias, como hemos venido haciéndolo. No existe un mundo indígena puro y libre de influencia de la cultura hegemónica, como nunca existió en la modernidad un régimen comunitarista puro y libre de influencia del capitalismo, incluso las poblaciones indígenas en aislamiento forzado tienen, como se comentará en el último capítulo, influencia de la modernidad. Tampoco se puede negar la complejidad del mundo moderno globalizado en la que se encuentran incertas las comunidades indígenas y las doctrinas que promueven la emancipación. Hay contradicciones y tenemos que ser críticos y asumirlas.

De las tres corrientes que hemos enunciado, nos quedamos con esta tercera forma de aproximarnos al sumak kawsay porque esta es la única vía que puede ayudarnos a encontrar luces para superar al capitalismo y nos permite dialogar con otros saberes y prácticas emancipatorias. El sumak kawsay combate la idea de desarrollo y al capitalismo (ACOSTA, 2011, p. 55) y, como afirma Quijano, "la propuesta es, necesariamente, una cuestión histórica abierta que requiere ser continuamente indagada, debatida y practicada" (2011, p. 87).

\subsection{El sumak kawsay otra forma de vida}

En La caverna de José Saramago podemos apreciar en funcionamiento el encuentro de estos dos sistemas de vida, el hegemónico capitalista basado en el desarrollo y el que pregona el sumak kawsay. Cipriano Algor es un alfarero. Trabaja con sus manos la arcilla: sacar tierra, mezclar con agua, batir, amasar la pasta, tornear las piezas, cocer en el horno (SARAMAGO, 2000, p. 27). Tiene un horno heredado de su padre, que a su vez heredó de su abuelo. Hace vajillas y las vende con exclusividad al Centro. Cipriano tiene claro la diferencia entre el valor de uso y cambio. "Lo más importante es el trabajo que hace, no la utilidad que tenga, si le quitas el trabajo, cualquier trabajo, le quitas, en cierto modo, una razón de vivir" (SARAMAGO, 2000, p. 299). El plástico terminará desplazando a la arcilla. Cipriano tiene una hija, Marta, que 
le ayuda en la alfarería. Marta está casada con Marcial Gacho, que es un guardia de seguridad en el Centro. Marcial sueña con ser ascendido, ser un guardia residente y, por tanto, vivir dentro del Centro. A estos personajes, hay que mencionar a Encontrado, el perro, que llega a la casa a quedarse, reclama atención a sus necesidades, se dedica a llenar afectos y a hacer sentir a los seres humanos que responde a sus expectativas (SARAMAGO, 2000, p. 81). Finalmente, el "Centro" es un personaje más, que no solo le da contexto a la obra sino también que tiene vida y muerte propia. El centro comercial es un edificio grande, sin ventanas, cerrado, hiper seguro, lleno de comercios y actividades recreativas, trabajadores, transeúntes y, sobretodo, consumidores. El Centro es un "impenetrable paño de muralla donde los paneles suspendidos que prometen seguridad no pueden ser responsabilizados de tapar la luz y robar el aire a quien vive dentro" (SARAMAGO, 2000, p. 131). La vida del alfarero refleja la propuesta del sumak kawsay y el Centro, en cambio, la de desarrollo capitalista.

El Centro gira alrededor de las mercancias. "El producto interesa, o el producto no interesa, el resto es indiferente" (SARAMAGO, 2000, p. 84). "Nada, cero, esto es lo que somos para ellos, cero", descubre Cipriano (SARAMAGO, 2000, p. 129). El Centro es como un tribunal implacable. Para ellos "lo que ha dejado de tener uso se tira, incluyendo a las personas" (SARAMAGO, 2000, p. 170). Para ellos, "los alfareros se están acabando" (SARAMAGO, 2000, p. 171). En el Centro todo se controla, "con patrullas de policía verificando carnés de conducir, pólizas de seguros y certificados de salud. Tal vez no hay otra manera de vivir, $O$ tal vez sea demasiado tarde para que haya otra manera" (SARAMAGO, 2000, p. 272). En el Centro, y este no es un detalle menor, no se admiten perros (SARAMAGO, 2000, p. 300). “Aquí nunca se acaban las obras, el Centro crece todos los días" (SARAMAGO, 2000, p. 364). El Centro es un perfecto vendedor de bienes materiales y esprituales. Gracias al Centro, "la vida adquiere un nuevo sentido para millones y millones de personas que andaban por ahí infelices, frustradas, desamparadas, es decir, quiera o no se quiera, esto no es una obra de materia vil, sino de espíritu sublime" (SARAMAGO, 2000, p. 379).

El yerno, inserto en el sistema y en la idea de superarse para ganar más sueldo y prestigio, es ascendido y tiene que ir a vivir dentro del Centro. La vida en el edificio, comparada con la casa a las afueras de la ciudad, también nos permiten contrastar el sumak kawsay con el desarrollo. En el departamento no hay como abrir las ventanas, el aire es enlatado, y es un departamento pequeño, que no permite más que tres miembros de familia. Cipriano, resignado a vivir en el Centro, se dedica a pasear, R. Fac. Dir. UFG, v. 41, n.1, p. 166-197, jan. / jun. 2017 
El Sumak Kawsay y el Yasuní: contradicciones, disputas y esperanzas. Una alternativa al capitalismo

vaguear y explorar cada rincón del Centro. Un día le piden a Marcial una misión especial, que solo la pueden hacer los residentes. Deben hacer turnos extras y cuidar la excavación. Todo lo que vieren u oyeren es un secreto. Algo se descubrió en la gruta cuando la tierra era removida. Marta se imaginó que encontraron petróleo, una mina de diamantes o la piedra que señala el sitio del ombligo del mundo" (SARAMAGO, 2000, p. 414). Cipriano descubre cadáveres y llora. "Quiénes son esas personas, Esas personas somos nosotros, dijo Cipriano Algor" (SARAMAGO, 2000, p. 436). Cipriano actúa y resiste: abandona el departamento. Tres semanas después, regresó a su casa, al encuentro de Isaura y de Encontrado. Días más tarde, Marcial pidió la baja como guarda y dejó de ser empleado del Centro. "Quien no se ajusta no sirve, y yo ya había dejado de ajustarme" (SARAMAGO, 2000, p. 450).

Quisiera establecer algunas comparaciones para marcar la diferencia de forma clara y esquemática entre los dos modelos de organización social y económica que se encuentran en la historia de Saramago. El Centro crece sin límites para todo lado, arriba y abajo, y a los lados. Cipriano vive al día y con lo suficiente. El Centro tiene como motor la mercancía que tiene que ser vendida. Si no se vende, no sirve para nada, y esto sucedió con los objetos de arcilla frente a los de plástico. Cipriano regala las piezas y finalmente las convierte en un objeto arqueológico. La naturaleza para el Centro es un objeto de apropiación y un espacio para la construcción. El bosque estorba. Cipriano tiene una relación afectiva con la arcilla, a la que trata con respeto y consideración. Todos compiten en el Centro, por vender más o por ascender. En la alfarería de Cipriano el lucro no es un objetivo sino la interrelación entre los miembros y la vivencia diaria. En el Centro no se saben de dónde vienen las órdenes ni quién se beneficia de toda la venta. En la alfarería Cipriano y la familia tienen control sobre lo que producen sus manos y sus tiempos, quieren lo que hacen. La familia al final nos da una lección de dignidad, renuncia la centro, al trabajo, a la ciudad, porque prefieren la libertad antes que la sumisión. La palabra que describe al desarrollo capitalista, y la vida que ofrece el Centro, sería llaki kawsay, mal vivir, que sería un mundo sin sabiduría, sin experiencia propia, carente de vida comunitaria, sin valores propios, sin relación con la naturaleza (HIDALGO-CAPITÁN, 2014, p. 51). El estilo de vida del Centro es incompatible con la dignidad de las personas. Así como la familia de Cipriano, en donde los miembros no se mueven por el lucro, existen prácticas del sumak kawsay en la cotidianidad de muchas de las comunidades indígenas andinas. 


\begin{tabular}{|c|c|c|}
\hline $\begin{array}{l}\text { Principios del } \\
\text { sumak kawsay }\end{array}$ & Sumak kawsay: la alfarería & Llaki kawsay: El Centro \\
\hline \multirow[t]{4}{*}{ 1. Relacionalidad } & $\begin{array}{l}\text { Cipriano, familia, el perro, la } \\
\text { arcilla: todos conectados }\end{array}$ & El Centro: aislado. \\
\hline & $\begin{array}{l}\text { Los seres son libres y se } \\
\text { respetan e interrelacionan: } \\
\text { bosques, jardín, cultivar flores, } \\
\text { cuidar perro, seres humanos. }\end{array}$ & $\begin{array}{l}\text { La industria oprime. El invernadero } \\
\text { "máquina de hacer vegetales." Los } \\
\text { seres prescindibles. "Cinturón } \\
\text { verde" es basura y desierto. }\end{array}$ \\
\hline & $\begin{array}{l}\text { El "el barro es natural" y } \\
\text { moldeado por el alfarero }\end{array}$ & $\begin{array}{l}\text { Plástico más barato y resistente, } \\
\text { hecho por una fábrica. }\end{array}$ \\
\hline & $\begin{array}{l}\text { La naturaleza es real y está en } \\
\text { todo. }\end{array}$ & $\begin{array}{l}\text { Todo es imitación de la naturaleza } \\
\text { (la arena, el aire enlatado). }\end{array}$ \\
\hline \multirow[t]{7}{*}{ 2. Reciprocidad } & $\begin{array}{l}\text { Las vasijas de barro tienen } \\
\text { múltiples usos: valor de uso. }\end{array}$ & $\begin{array}{l}\text { Las vasijas tiene valor si se venden: } \\
\text { valor de cambio. }\end{array}$ \\
\hline & $\begin{array}{l}\text { Vasija recipiente, adorno, pieza } \\
\text { arqueológica. }\end{array}$ & Mercancía. \\
\hline & $\begin{array}{l}\text { El dinero facilita intercambio y } \\
\text { medio para satisfacer } \\
\text { necesidades vitales. }\end{array}$ & $\begin{array}{l}\text { El dinero representa valor de } \\
\text { cambio (precio) y se acumula. }\end{array}$ \\
\hline & $\begin{array}{l}\text { Se crece solo si necesidad de } \\
\text { subsistencia. }\end{array}$ & $\begin{array}{l}\text { Crecimiento sin límites (El Centro } \\
\text { crece para arriba, costados y abajo). }\end{array}$ \\
\hline & Producir para ser. & Producir para tener más. \\
\hline & $\begin{array}{l}\text { Actividad económica para hacer } \\
\text { vínculos: con hija, yerno, } \\
\text { consumidor, vendedor. }\end{array}$ & $\begin{array}{l}\text { Lucro. El vínculo es entre bienes, } \\
\text { no entre personas. }\end{array}$ \\
\hline & $\begin{array}{l}\text { Capital no se acumula: se gasta } \\
\text { para sobrevivencia. }\end{array}$ & $\begin{array}{l}\text { Capital se concentra (monopolio) y } \\
\text { circula. }\end{array}$ \\
\hline \multirow[t]{3}{*}{$\begin{array}{l}\text { 3. } \\
\text { Complementariedad }\end{array}$} & $\begin{array}{l}\text { Vivir como una planta: hay que } \\
\text { cuidar para que crezca. }\end{array}$ & $\begin{array}{l}\text { Vivir para ascender y ganar más } \\
\text { sueldo: carrera individual. }\end{array}$ \\
\hline & Trabajo: relación social. & Trabajo productivo, para vender. \\
\hline & $\begin{array}{l}\text { Solidaridad entre miembros } \\
\text { familia y comunidad. }\end{array}$ & $\begin{array}{l}\text { Competencia. Apropiación (robo y } \\
\text { explotación). }\end{array}$ \\
\hline \multirow[t]{5}{*}{ 4. Correspondencia } & $\begin{array}{l}\text { Arcilla-trabajo alfarero: razón } \\
\text { existencia mutua. }\end{array}$ & $\begin{array}{l}\text { El centro: importa su ganancia, no } \\
\text { los materiales, no el cuidado, no la } \\
\text { forma de trabajo. }\end{array}$ \\
\hline & $\begin{array}{l}\text { Reconocimiento del "otro", de } \\
\text { su tiempo, del material, del } \\
\text { trabajo. }\end{array}$ & $\begin{array}{l}\text { Explotación: "se derriten de sudor } \\
\text { dentro..." }\end{array}$ \\
\hline & Toda actividad es valorada. & $\begin{array}{l}\text { El valor del trabajo depende de } \\
\text { status. }\end{array}$ \\
\hline & $\begin{array}{l}\text { Igualdad en las relaciones de } \\
\text { producción. }\end{array}$ & Poder: dominación-sumisión. \\
\hline & $\begin{array}{ll}\text { Libertad, } & \text { creatividad } \\
\text { curiosidad. }\end{array}$ & $\begin{array}{l}\text { Control: seres hacen lo que deben/ } \\
\text { sospechoso/ interrogación/ cámaras. }\end{array}$ \\
\hline \multirow[t]{4}{*}{$\begin{array}{l}\text { 5. Afectividad/ } \\
\text { espiritualidad }\end{array}$} & $\begin{array}{l}\text { Conciencia alienación. Sentir } \\
\text { opresión. }\end{array}$ & $\begin{array}{l}\text { Centro "espíritu sublime", da } \\
\text { sentido a millones de vida }\end{array}$ \\
\hline & Familia integrada. & Soledad. \\
\hline & $\begin{array}{l}\text { Vínculo afectivo con la arcilla, } \\
\text { con la casa, con el horno, con } \\
\text { los seres humanos. }\end{array}$ & $\begin{array}{l}\text { El único vínculo aceptado es el } \\
\text { mediado por la ganancia. }\end{array}$ \\
\hline & $\begin{array}{l}\text { Tecnología (horno) ayuda al ser } \\
\text { humano, permite la interacción y } \\
\text { la compasión. }\end{array}$ & $\begin{array}{l}\text { Tecnología para controlar, } \\
\text { acumular, separa y mata (cámaras, } \\
\text { armas, vigilancia, informática). }\end{array}$ \\
\hline
\end{tabular}


El Sumak Kawsay y el Yasuní: contradicciones, disputas y esperanzas. Una alternativa al capitalismo

\begin{tabular}{|c|c|c|}
\hline & Perro ser solidario. & $\begin{array}{l}\text { El perro es un estorbo y se le } \\
\text { prohíbe entrar a Centro }\end{array}$ \\
\hline \multirow[t]{3}{*}{ 6. Ciclicidad } & $\begin{array}{l}\text { Las figuras de arcilla se hacen y } \\
\text { rehacen hasta que tengan } \\
\text { formas. }\end{array}$ & El proceso productivo es lineal. \\
\hline & $\begin{array}{l}\text { El trabajo termina y comienza } \\
\text { en cada horneada. }\end{array}$ & $\begin{array}{l}\text { El trabajo (yerno) es una carrera de } \\
\text { ascenso (hasta la jubilación) }\end{array}$ \\
\hline & $\begin{array}{l}\text { Varias vidas en una vida: } \\
\text { alfarería, el centro, y la apertura } \\
\text { para otra. }\end{array}$ & Una vida sacrificada y competitiva. \\
\hline \multirow[t]{4}{*}{ 7. Comunitarismo } & La arcilla: bien común. & $\begin{array}{l}\text { El centro y la mercancía: propiedad } \\
\text { privada, expansiva y excluyente. }\end{array}$ \\
\hline & $\begin{array}{l}\text { Personas concretas } \\
\text { interrelacionan. }\end{array}$ & $\begin{array}{l}\text { Los dueños, los } \\
\text { invisibles y toman } \\
\text { secretas. }\end{array}$ \\
\hline & $\begin{array}{l}\text { Control colectivo (familiar) } \\
\text { sobre producción y producto. }\end{array}$ & $\begin{array}{l}\text { Trabajadores no control sobre } \\
\text { medios de producción ni producto. }\end{array}$ \\
\hline & $\begin{array}{l}\text { La alfarería: espacio y actividad } \\
\text { abierta. }\end{array}$ & $\begin{array}{l}\text { El centro: espacio cerrado y } \\
\text { actividades restringidas. }\end{array}$ \\
\hline 8.Sumak kawsay & Vida plenitud. & $\begin{array}{lll}\begin{array}{l}\text { Soledad, } \\
\text { (muerte). }\end{array} & \text { desierto, } & \text { violencia } \\
\end{array}$ \\
\hline
\end{tabular}

Como se puede apreciar, si es que se aplican los principios del sumak kawsay a La caverna, la forma de experimentar la vida es diametralmente opuesta al modelo de desarrollo capitalista. Por ello, Alberto Acosta afirma que el sumak kawsay "no solo critica el desarrollo, lo combate" (2012, p. 224) o, como sostiene Crespo, es la antípoda del desarrollo (2013, p. 55) y la superación del sistema capitalista (LLASAG 2009, p. 119). Aplicar las recetas del siglo pasado relacionadas con la noción del desarrollo, crecimiento, progreso, neoliberalismo puede ser un camino al fracaso si se quiere caminar hacia el sumak kawsay. Por otro lado, la idea es encontrar el sumak kawsay no solo en el mundo indígena sino en toda práctica y experiencia no capitalista.

\section{EL YASUNÍ: EL LUGAR CONCRETO DEL CAPITALISMO DEPREDADOR Y DEL SUMAK KAWSAY}

¿Qué valen unos pocos machetes y teteras comparadas con la reserva de caza ilimitada que siempre han disfrutado?

¿Cómo pueden confiar en nuestra buena voluntad cuando los cazamos tan implacablemente?

Están tan desesperados por esconderse de fuerzas que ellos no entienden, ipero cuánto más desesperados estarían si realmente entendieran! 
Hermana Catherine Peeke, 1968.

El Yasuní es un espacio territorial que queda en la Amazonía ecuatoriana. El Yasuní, que fue declarado parque nacional y patrimonio natural y cultural de la humanidad por la UNESCO, es un refugio del pleistoceno y una de las zonas con mayor biodiversidad del planeta (ÁLVAREZ, 2012, p. 80), que alberga 165 de especies de mamíferos, 110 de anfibios, 72 de reptiles, 630 aves, 1.130 de árboles, y miles de especies de invertebrados no estudiados (ACOSTA, 2009, p. 190). La riqueza humana también es impresionante. En la zona encontramos ocho minorías lingüísticas "que atraviesan y se expanden por nociones territoriales propias y que dependen de la selva para el mantenimiento de sus culturas" (FRANCO, 2012, p. 142), de esas minorías hay dos pueblos, los Taromenani y los Tagaeri, que huyen de la cultura occidental y se consideran Pueblos Indígenas en Aislamiento (PIA). También, desde otra mirada, existe mucha riqueza valorada por la cultura occidental hegemónica: petróleo, madera y patrimonio genético.

En ese lugar privilegiado encontramos las más grandes contradicciones que se pueden producir en la vida moderna. Por un lado, habitan pueblos en aislamiento forzado, fuera de la modernidad, cuya riqueza es la selva y la comunidad, que rechazan y resisten a la modernidad occidental, que demuestran que se puede vivir sin capitalismo y que la utopía andina es posible. Por otro lado, en el mismo territorio, encontramos mestizos, extranjeros y pueblos indígenas que experimentan y practican las peores prácticas de la modernidad capitalista, y para quienes la selva es un lugar donde todo se vende y se compra. El Yasuní, como afirma el geógrafo y profesor Massimo De Marchi, es un lugar donde actualmente se disputa la producción territorial del buen vivir o una herramienta de distracción que sigue el proyecto extractivo (2012, p. 82).

\subsection{La iniciativa Yasuní ITT}

La "Iniciativa Yasuní ITT" consistía en dejar bajo tierra 850 millones de barriles de petróleo, que se calculaba significaría 410 millones de toneladas de $\mathrm{CO}^{2}$ en la atmósfera a cambio de una compensación monetaria equivalente a la mitad de lo que se obtendría en dinero (NARVÁEZ et al. 2012, 10; ACOSTA, 2009, p. 190).

Los pilares del Yasuni ITT eran la conservación de la biodiversidad, la protección de los pueblos en aislamiento, el cuidado del clima, y dar el primer paso transición postpetrolera (ACOSTA, 2012, p. 219). Acosta sostiene que mantener bajo 
El Sumak Kawsay y el Yasuní: contradicciones, disputas y esperanzas. Una alternativa al capitalismo

tierra el petróleo tiene implicaciones éticas, sociales, económicas no cuantificables en dinero, como "evitar la extinción de la cultura waorani, cuya subsistencia se ha basado en la caza, recolección y agricultura itinerante", ahorraría al mundo el abatimiento de la atmósfera, evitaría la deforestación y protegería la zona de mayor diversidad del planeta (ACOSTA, 2009, p. 190).

Expedida la Constitución de Montecristi, inmediatamente muchos ciudadanos, políticos y académicos asociaron la iniciativa con el sumak kawsay y con la pachamama. "La fuerza del sumak kawsay es la de representar un modelo que va más allá del desarrollo sostenible y, si bien ha conceptualizado el punto de llegada, tiene que conceptualizar la transición. La herramienta para conceptualizar y comunicar la transición es el ícono "Yasuní-ITT"” (NARVÁEZ et al. 2013, p. 21). "La iniciativa Yasuní ITT representa una prueba de vida, por lo que se presenta como una salida futurista a los problemas del planeta" (LÓPEZ, 2013, p. 237).

Sin embargo, la iniciativa adolecía de algunas de imprecisiones e incluso contradicciones con la noción del sumak kawsay y de la pachamama: se organizó un fideicomiso para la administración del dinero recolectado, que podría ser canjeado o devuelto si se explotaba el petróleo, siempre hubo un doble discurso con la ameneza de explotar el petróleo si no había ayuda financiera, el valor del parque se expresaba en dinero y de acuerdo a la cotización del petróleo, hubo cambios en los equipos negociadores y de los discursos conservacionistas a mercantilistas (DE MARCHI, 2013, p. 279).

El 23 de agosto de 2013, bajo el argumento de que la comunidad internacional no ha asumido su responsabilidad frente a la propuesta conservacionista del Ecuador y que somos mendigos sentados en una bacinilla de oro (LÓPEZ, 2013, p. 235), el presidente pidió a la Asamblea Nacional que declare de interés nacional la explotación de petróleo en el Parque Nacional Yasuní. ${ }^{9}$ En el mes de octubre de 2013, la Asamblea Nacional decidió declarar de interés nacional la explotación de petróleo en el Parque Nacional Yasuní, bajo el argumento de que los recursos producto de la explotación del petróleo contribuirá al desarrollo del país y a combatir la pobreza.

La respuesta ciudadana no se hizo esperar. Hubo protestas, los ciudadanos se organizaron, reunieron firmas para realizar una consulta popular con el objeto de que una decisión tan importante, que no ponía en riesgo la sobrevivencia de PAI y la biodiversidad del Yasuní, no podía ser tomada por el presidente ni por los asambleístas. 
Se consiguieron las firmas, pero el Estado, a través de la Corte Constitucional, el Consejo Electoral y por pronunciamientos del mismo presidente, negó la consulta.

Al momento, en algunos sectores se está explotando el petróleo, en la zona intangible se han realizado ya labores de prospección, y se siguen produciendo actos de violencia en la zona y en zonas aledañas se está explotando el petróleo. En otras palabras, según Aguirre, con la autorización del Estado "madereros ilegales, petroleros y colonos, todos ellos juntos van achicando el territorio de los taromenani como una soga de civilización atada al cuello de los no contactados" (Discovery Chanel, 2014).

\subsection{Los waoranis}

Los waoranis hablan "wao tededo", que es un idioma que no tiene filiación con familias lingüísticas sudamericanas y es "única en la cuenca amazónica continental" (FRANCO, 2013, p. 145). Wao significa persona y el plural es waorani (SANTOS, 1996, p. 12).

¿Desde cuándo están los Waoranis en la Amazonía? "Cien millones de años-afirma Santos- ha permanecido esta selva en silencio" (SANTOS, 1996, p. 11). ¿Francisco de Orellana, cuando hizo la expedición en búsqueda del País de la Canela y descubrió el río Amazonas, se encontró con los waoranis? No sabemos. La información etnohistórica es escasa y ambigua, y se confunde con los encuentros con otros pueblos indígenas amazónicos (FRANCO, 2013, p. 144). El primer contacto conocido de occidente con los waoranis se produce en el siglo XX, cuando se explotó el caucho en la Amazonía. En esta época, "los caucheros persiguieron a los waorani en su propio territorio, intentando someterlos para la recolección de la balata" y se conoce que, en varias ocasiones, los woaranis atacaron a las cuadrillas de peones caucheros (FRANCO, 2013, p. 143).

El segundo contacto violento de occidente con los waorani se produce en 1955, cuando la empresa Texaco comienza sus operaciones en la Amazonía, y cuando las misiones religiosas, evangélicas (Instituto Lingüistico de Verano - ILV) y católicas, inician el proceso de "civilización" de los "primitivos" y "salvajes." Estas misiones facilitarían las tareas de explotación petrolera. En 1956, cuando se estableció el ILV, según un censo elaborado por ellos, existían 500 waoranis y todos eran no contactados.

Los pueblos y las comunidades colindantes al Yasuní son atacadas constantemente por waoranis. Santos registra desde 1959 hasta 1968, que es cuando la Texaco comienza a explotar petróleo, 12 personas muertas por lanzas de los waoranis. 
El Sumak Kawsay y el Yasuní: contradicciones, disputas y esperanzas. Una alternativa al capitalismo

Todos los "invasores" tienen víctimas y mártires de los waoranis. Han muerto kichwas, colonos, madereros, petroleros, misioneros evangélicos y capuchinos e, incluso, waoranis contactados. En los años 70, la producción de petróleo es intensiva. Las empresas petroleras en general no tenían interés en el contacto, salvo cuando eran afectadas por ataques, consideraban que era un estorbo y que afectaba sus labores. "La verdadera cara de la prospección petrolera para la que, en la práctica, sólo importa el dinero y el petróleo, y nada absolutamente la supervivencia de una minoría a punto de extinguirse" (SANTOS, 1996, p. 103).

En 1990 los indígenas forman la Organización Hoarani Nacional del Ecuador (OHNAE), que actualmente se conoce como Organización Nacional Waorani del Ecuador (ONAWE), que originalmente se formó para impedir la expansión de la frontera agrícula y petrolera, y que acabaría siendo cooptada por los programas de desarrollo comunitario de las empresas petroleras (FRANCO, 2013, p. 166).

A pesar de las delimitaciones territoriales, que comenzaron cuando se declaró Parque Nacional (1979), Reserva mundial de la biósfera (1989), zona intangible (1999), y de las protecciones jurídicas, como las medidas cautelares de la CIDH (2006), y el reconocimiento constitucional de los derechos específicos de las poblaciones indígenas y de los pueblos en aislamiento (2008), en el Yasuní se sigue explotando el petróleo y la madera, y han habido múltiples escenas de violencia entre los waoranis entre sí y con las poblaciones mestizas: en el 2003 mueren veinte Taromenani a manos de nueve waoranis contactados "impulsados por los intereses de inescrupulosos patrones madereros" (AGUIRRE, 2013, p. 429), en el 2009 mueren seis personas lanceados por PAI, en el 2011 hubo otro muerto, y en el año 2013 se produce la masacre de aproximadamente treinta Taromenanis.

Todas las muertes tienen varias cuestiones en común: se producen dentro y fuera del Parque Nacional Yasuní, muchos fuera de la zona intangible; todos los contactos con los Tagaeri y Taromenani son violentos; todas las muertes están en la impunidad (nunca ha habido una investigación estatal seria y peor alguna persona condenada); en todas están involucradas "gentes a las que nos empeñamos en ocultar" (AGUIRRE, 2013, p. 427).

Tenemos, pues, dos grupos de waoranis. Los contactados o "civilizados" y los pueblos indígenas en aislamiento (PIA). Los unos, incluídos en el área de los pozos petroleros y de influencia religiosa, civilizados, mientras los Taromenani y Tagaeri, 
excluídos, lo hacen en zonas salvajes (SANTOS, 2003, p. 84). Los contactados viven la modernidad capitalista y los PIA resisten a la invasión cultural. ¿En qué medida en esta pequeña zona del mundo, el Yasuní, econtramos tanto la distopía del capitalismo como la utopía del buen vivir?

Los waoranis contactadosson de acuerdo al último censo del año 2010, aproximadamente 2.200 personas. Los waoranis han sufrido un proceso de aculturación. Las misiones religiosas cambiaron radicalmente las formas de vida y subsistencia de los waoranis contactados: de las actividades de recolección y caza, los waoranis se convirtieron en productores de chacra y cuidadores de animales domésticos; de pueblos que vivían de la abundancia de selva, pasaron a depender de los productos de ciudad (como azúcar, aceite y enlatados) que eran y son proporcionados por las empresas petroleras. Los misioneros del ILV les impusieron nuevos tipos de conducta y les obligaron a abandonar otras. Los misioneros combatieron las prácticas guerreras, los matrimonios poligínicos y poliándricos, las prácticas ceremoniales como fiestas, cantos y danzas, los espacios sagrados naturales, la desnudez; y aprendieron nuevas técnicas de caza con armas de fuego, nuevas formas de vestir y construir las casas, las familias se tornaron nucleares y se promovió la monogamia, la procreación limitada; también comenzaron a utilizar la radio, el transporte terrestre y acuático, se volvieron sedentarios, y aprendieron a convivir con los enemigos caworis y nanicabos (FRANCO, 2013, p. 151).

Muchos waoranis se han integrado al mundo moderno capitalista y la relativa autodeterminación que tenían antes de ser "civilizados" ha sido reemplazada por "la cooptación casi absoluta del pueblo waorani por parte de empresas transnacionales, de las ONG, o instituciones burocráticas" (NARVÁEZ, 2013, p. 44). Hay waoranis que trabajan como monitores para el Programa de Medidas Cautelares (PMC), hay petroleros, que han formado el consorcio OMEKE (Cantarida y SERTECPEC), no tienen capital pero conocen la zona y son los únicos que incursionan en la selva para hacer huir o matar a los Taromenani y Tagaeri (AGUIRRE, 2013, p. 438). Alrededor de los pozos petroleros los colonos construyen bares, prostíbulos, tiendas cerca de los campamentos. A estos lugares, con frecuencia, ahora visitan los waoranis "toman alcohol y en algunos casos han adquirido enfermedades venéreas" (AGUIERRE, 2013, p. 162). La relación de la petrolera con algunos waoranis es asistencial y, como muchas relaciones clientelares, genera personas dependientes, pasivas e inútiles (NARVÁEZ, 2013, p. 37). Antes los waoranis vendían animales que R. Fac. Dir. UFG, v. 41, n.1, p. 166-197, jan. / jun. 2017 
El Sumak Kawsay y el Yasuní: contradicciones, disputas y esperanzas. Una alternativa al capitalismo

cazaban a militares y petroleros. Ahora, si los cocineros de los campamentos no les dan comida, los waoranis saquean. Las compañías petroleras abastecen a las comunidades waoranis de víveres, herramientas y vestidos (AGUIRRE, 2013, p. 165). Algunas comunidades, como Gareno, han emigrado y se han asentado junto a empresas petroleras porque "la presencia de las operaciones petroleras atrae a algunos waorani como un imán, con la ilusión de que estos proveen dádivas, empleo y opulencia” (LU et al. 2012, p. 114). Un ejemplo de waorani “civilizado", Babe: participa en el negocio de la madera y cobra un dólar por tablón de madera, participó en una cruenta matanza a mujeres y niños Taromenani en la selva del Curaray (AGUIRRE, 2007, p. 23); recibe, en Tigüino, salario de la compañía petrolera (AGUIRRE, 2007, p. 43). A los turistas Babe cobra entrada y salida, por lucir cerbatanas, pide coca cola y hasta motor para su canoa (AGUIRRE, 2007, p. 63), vende lanzas de los Taromenani en 100 dólares.

Pero hay otros waoranis, los Taromenani y los Tagaeri, que huyen de nuestra cultura dominante y que luchan con sus lanzas por un mundo que no es moderno ni capitalista. Algunos rasgos conocemos por los ancianos waorani que recuerdan su forma de vida cuando eran no contactados. La unidad básica es el nanicabo conformada por 30 a 50 personas autosuficientes y autónomas, que viven bajo el mismo techo. (LU et al. 2012, p. 116).La organización política tradicional es igualitaria y comunitarista. "No hay jefes ni hombres nacidos en puestos de poder, los roles de género son flexibles y existe el mismo valor entre ambos sexos; una persona no puede imponer su voluntad sobre la otra. Para tener una buena posición social, no hay que robar ni engañar (LU et al. 2012, p. 116). La tierra, los animales y los instrumentos que tienen son comunitarios para la caza, pesca y la siembra (LU et al. 2012, p. 117).

Para los waorani el negar alimentos a alguien que les pide es básicamente negar cualquier tipo de relación con esa persona. El intercambio de alimentos fundamental. Las mujeres cuyos maridos estaban lejos por un largo tiempo eran las destinatarias de los alimentos compartidos. En Huentaro se reparten los alimentos entre todos los hogares varias veces por semana (LU et al. 2012, p. 119).

Un waorani nunca va a dormir con hambre (LU et al. 2012, p. 119). "Aquí vivimos bien, hay de todo. La tierra es buena, aquí hay comida, no es necesario comprar. No hay dinero para vivir. A los jóvenes se les debe entrenar para defender el territorio, para no permitir que los madereros y las empresas petroleras entren, para 
cuidar la tierra" (LU et al. 2012, p. 148). Las tierras no tienen dueño y nunca están abandonadas(LU et al. 2012, p. 126).

Cuando se les preguntó sobre lo que la comunidad consideraba sumak kawsay, manifestaron "una buena vida significa bailar danzas tradicionales, bailar con tocados, beber mucha chicha, hablar, ser respetuoso y cantar canciones. Vivir sin problemas o sin malas influencias, sin conflictos con otras personas y sin enemigos" (LU et al. 2012, p. 144). Al mismo tiempo, el fundador de la comunidad Huentaro expresa su visión de comunidad e introduce valoraciones sobre las actividades extractivas, que nos permiten entender por qué los Taromenani y Tagaeri huyen:

Tenemos que vivir como nuestros abuelos, ser fuertes como nuestros abuelos, tener la entereza para denunciar a los foráneos cuando nos hacen cosas malas. La gente tiene que ser fuerte. Nadie va a hacer problemas o lios aquí, porque somos guerreros, vamos a matar, vamos a trabajar fuerte, nunca vamos a fallar, nos defendemos a nosotros mismos. Vamos a vivir tranquilos... vamos a vivir como nuestros antepasados, nunca saldremos de nuestra cultura. Las carreteras interfieren con el movimiento de animales y el ruido ahuyenta a los animales. Las carreteras traen colonos y madereros que utilizan los recursos. Las carreteras dan la posibilidad de aumentar el contacto con los ladrones y la guerrilla. Con la carretera, las niñas, las mujeres, los esposos se van, hay enfermedades, basura y entra la contaminación. Era mejor tener la selva intacta, más que una carretera. La selva es importante para el futuro, para todos, no solo ahora (LU et al. 2012, p. 144-145).

En Ecuador el sumak kawsay no solo es una alternativa al capitalismo, reconocida en la Constitución, una noción en constante disputa, sino también es una forma de vida que lucha por mantenerse, y esto es lo que nos demuestran los Tagaeri y los Taromenani a quienes los agentes de la modernidad, petroleras, madereras, empresas de turismo y grupos religiosos están matando. El sumak kawsay del constitucionalismo transformador andino es, pues, una lucha, una disputa de poder y una esperanza, la esperanza de un mundo distinto al que nos ofrece el capitalismo. Una opción para vivir en plenitud.

\section{BIBLIOGRAFÍA}

Acosta, Alberto (2009). La maldición de la abundancia. Quito: Abya Yala.

Acosta, Alberto (2011). "Riesgos y amenazas para el Buen Vivir", en Centro Andino de Acción Popular. Acerca del Buen Vivir. Ecuador Debate N. 84. Quito: CAAP. 
El Sumak Kawsay y el Yasuní: contradicciones, disputas y esperanzas. Una alternativa al capitalismo

Acosta, Alberto (2012). Buen vivir Sumak kawsay. Una oportunidad para imaginar otros mundos. Quito: Abya Yala.

Aguirre, Milagros (2007). ¡A quién le importan esas vidas!: Un reportaje sober la tala ilegal en el Parque Nacional Yasuní. Quito: CICAME.

Aguirre, Milagros (2013). “¡Ocultados! La bitácora de unas muertes anunciadas (marzoseptiembre 2013)", en Miguel Angel Cabodevilla y Milagros Aguirre (2013). Una tragedia ocultada. Quito: CICAME/Fundación Alejandro Labaka.

Albó, Xavier (2009). Suma qamaña = el buen convivir, en https://sumakkawsay.files.wordpress.com/2009/06/albo_sumaqamana.pdf (acceso 17 de marzo 2015).

Álvarez, Yomar ."Una propuesta desde el ecologismo para proteger a una parte del Parque Nacional Yasuní”, en Iván Narváez, Massimo De Marchi y Salvatore Eugenio Pappalardo (coordinadores) (2012). Yasuní zona de sacrificio. Análisis de la iniciativa ITT y los derechos colectivos indígenas. Quito: FLACSO Ecuador.

Camp, Cassey (2014). "Opening Expert". Quito: Global Alliance for the Rights of Nature, en http://therightsofnature.org/casey-camp-horinek-opening-expert/ (acceso: 23 de enero 2015)

Chancosa, Blanca. "El Sumak Kawsay desde la visión de la mujer", en Antonio Luis Hidalgo-Capitán, Alejando Guillén García, Nancy Déleg Guazha (editores) (2014). Antología del pensamiento indigenista ecuatoriano sobre Sumak Kawsay. Huelva: CIM/FIUCUHU/Pydlos.

Crespo Barrera, Juan Manuel (2013). El Buen vivir: Del Sumak Kawsay y Suma Qamaña a las Constituciones del Buen Vivir. Contradicciones y desafío entre la teoría y la práctica. Donostia: Hegoa-Universidad del País Vasco.

Dávalos, Pablo. "Sumak Kawsay (La Vida en Plenitud)", en Antonio Luis HidalgoCapitán, Alejando Guillén García, Nancy Déleg Guazha (editores) (2014). Antología del pensamiento indigenista ecuatoriano sobre Sumak Kawsay. Huelva: CIM/FIUCUHU/Pydlos.

De Marchi, Massimo. “Territorios y representaciones: geografías del Yasuní”, en Iván Narváez, Massimo De Marchi y Salvatore Eugenio Pappalardo (coordinadores) (2012). Yasuní zona de sacrificio. Análisis de la iniciativa ITT y los derechos colectivos indígenas. Quito: FLACSO Ecuador.

Discovery Chanel, Genocidio en la selva: Yasuní. Discovery Max enhttps://www.youtube.com/watch?v=t4bQoVOt1k0

Dominguez, Rafael, y Caria, Sara (2014). La ideología del Buen Vivir: la metamorfosis de una "alternativa al desarrollo" en desarrollo de toda la vida, Quito: UASBEcaudor, en http://repositorio.uasb.edu.ec/bitstream/10644/3724/1/PRET-002- 
Dominguez-Car\%C3\%ADa-La\%20ideolog\%C3\%ADa.pdf (acceso 17 de marzo 2015).

Esterman, Josef. "Ecosofía andina. Una paradigma alternativo de convivencia cósmica y de vida plena", en Atawallpa Oviedo (2014). Bifurcación del buen vivir y el sumak kawsay. Quito: Ediciones SUMAK.

Franco, Juan Carlos. "Territorio waorani: problemática y el proceso extractivo en el Yasuní”, en Iván Narváez, Massimo De Marchi y Salvatore Eugenio Pappalardo (coordinadores) (2012). Yasuní zona de sacrificio. Análisis de la iniciativa ITT y los derechos colectivos indígenas. Quito: FLACSO Ecuador.

Galeano, Eduardo (2004). Las venas abiertas de América Latina. México: Siglo XXI Editores.

Giraldo, Omar Felipe (2014). Utopías en la era de la supervivencia. Una interpretación del buen vivir. México: Editorial Itaca.

Gudynas, Eduardo (2014). "Buen vivir: sobre secuestros, domesticaciones, rescates y alternativas", en Atawallpa Oviedo, Bifurcación del buen vivir y el sumak kawsay. Quito: Ediciones SUMAK.

Hidalgo-Capitán, Antonio Luis, Guillén García, Alejandro, Déleg Guazha, Nancy (editores) (2014). Antología del pensamiento indigenista ecuatoriano sobre Sumak Kawsay. Huelva: CIM/FIUCUHU/Pydlos.

Hidalgo-Capitán, Antonio Luis (2014b). "Seis debates abiertos sobre el sumac kawsay", en Flacso Ecuador, ÍCONOS, Revista de Ciencias Sociales, Número 48, Dossier: En busca del sumak kawsay. Quito: Flacso, Enero 2014.

Houtart, Francois. "El concepto de Sumak Kausay (Buen vivir) y su correspondencia con el buen común de la humanidad", en Centro Andino de Acción Popular (2011). Acerca del Buen Vivir. Ecuador Debate N. 84. Quito: CAAP

López Sánchez, Rodrigo (2012). "La conquista del paraíso y la explotación petrolera: Yasuní y Madidi", en Iván Narváez, Massimo De Marchi y Salvatore Eugenio Pappalardo (coordinadores). Yasuní zona de sacrificio. Análisis de la iniciativa ITT y los derechos colectivos indígenas. Quito: FLACSO Ecuador.

Lu, Flora, Bilsborrow, Richard E. y Oña, Ana Isabel (2012). Modos de vivir y sobrevivir. Un estudio transcultural de cinco etnias en la Amazonía ecuatoriana. Quito: Abya Yala/ Universidad Polítécnica salesiana.

Llasag, Raúl (2009). "El sumak kawsay y sus restricciones constitucionales", en Foro Revista de Derecho N. 12. Quito: UASB-Ecuador.

Llasag, Raúl (2013). "Movimiento indígena del Ecuador a partir del siglo XX: visibilizando el resurgir, sus avances y retrocesos", en Boaventura de Sousa Santos y Agustín Grijalva, Justicia indígena, plurinacionalidad e interculturalidad en Ecuador. Quito: Fundación Rosa Luxemburg/Abya Yala. 
El Sumak Kawsay y el Yasuní: contradicciones, disputas y esperanzas. Una alternativa al capitalismo

Mancilla, H.C.F. (2011). "Ideologías oficiales sobre el medio ambiente en Bolivia y sus aspectos problemáticos", en Centro Andino de Acción Popular, Acerca del Buen Vivir. Ecuador Debate N. 84. Quito: CAAP.

Medina, Javier (2014). "Vivir bien y de vita beata. Una cartografía boliviana", en Atawallpa Oviedo Bifurcación del buen vivir y el sumak kawsay. Quito: Ediciones SUMAK.

Monterroso, Augusto (1998). "Mister Taylor." Obras completas (y otros cuentos). Barcelona: Anagrama.

Narváez Q., Iván. “Los waorani en el Yasuní: contrapoder de los poderes salvajes”, en Iván Narváez, Massimo De Marchi y Salvatore Eugenio Pappalardo (coordinadores) (2012). Yasuní zona de sacrificio. Análisis de la iniciativa ITT y los derechos colectivos indígenas. Quito: FLACSO Ecuador.

Oviedo, Atawallpa (2014). "Capitalismo-Socialismo y Armonicidad”, en Antonio Luis Hidalgo-Capitán, Alejando Guillén García, Nancy Déleg Guazha (editores). Antología del pensamiento indigenista ecuatoriano sobre Sumak Kawsay. Huelva: CIM/FIUCUHU/Pydlos.

Oviedo, Atawallpa (2014b). "El postmoderno Buen Vivir y el ancestral Sumakawsay", en Antonio Luis Hidalgo-Capitán, Alejando Guillén García, Nancy Déleg Guazha (editores). Antología del pensamiento indigenista ecuatoriano sobre Sumak Kawsay. Huelva: CIM/FIUCUHU/Pydlos.

Oviedo, Atawuallpa (2014c). Bifurcación del buen vivir y el sumak kawsay. Quito: Ediciones SUMAK.

Pacari, Nina (2014). "Naturaleza y territorio desde la mirada de los pueblos indígenas",en Antonio Luis Hidalgo-Capitán, Alejando Guillén García, Nancy Déleg Guazha (editores). Antología del pensamiento indigenista ecuatoriano sobre Sumak Kawsay. Huelva: CIM/FIUCUHU/Pydlos.

Pacari, Nina (2014b). "Sumak Kawsay para que tengamos vida", en Antonio Luis Hidalgo-Capitán, Alejando Guillén García, Nancy Déleg Guazha (editores),Antología del pensamiento indigenista ecuatoriano sobre Sumak Kawsay. Huelva: CIM/FIUCUHU/Pydlos.

Quijano, Aníbal (2011). "Bien Vivir: entre el desarrollo y la des/colonialidad del poder", en Centro Andino de Acción Popular Acerca del Buen Vivir. Ecuador Debate N. 84. Quito: CAAP.

Sánchez Parga, José. "Discursos retrovolucionarios: Sumak Kausay, derechos de la naturaleza y otros pachamamismos", en Centro Andino de Acción Popular (2011). Acerca del Buen Vivir. Ecuador Debate N. 84. Quito: CAAP.

Santos Ortiz, Juan (1996). Los últimos huorani. Quito: CICAME. 
Santos, Boaventura de Sousa (2003). La caída del Angelus Novus: ensayos para una nueva teoría social y una nueva práctica política. Bogotá: ILSA/Universidad Nacional de Colombia.

Santos, Boaventura de Sousa (2006). De la mano de Alicia. Lo social y lo político en la posmodernidad. Bogotá: Siglo del Hombre Editores/Ediciones Uniandes.

Santos, Boaventura de Sousa (2010). Refundación del Estado en América Latina. Perspectivas desde una epistemología del Sur. Quito: Abya Yala.

Santos, Boaventura de Sousa (2013). "Cuando los excluidos tienen Derecho: justicia indígena, plurinacionalidad e interculturalidad", en Boaventura de Sousa Santos y Agustín Grijalva, Justicia indígena, plurinacionalidad $e$ interculturalidad en Ecuador. Quito: Fundación Rosa Luxemburg/Abya Yala.

Saramago, José (2000). La caverna. Perú: Alfaguara.

Sarayaku (2003). "El libro de la vida de Sarayaku para defender nuestro futuro", en Antonio Luis Hidalgo-Capitán, Alejando Guillén García, Nancy Déleg Guazha (editores) (2014). Antología del pensamiento indigenista ecuatoriano sobre Sumak Kawsay.

SENPLADES (2013). Buen vivir. Plan nacional 2013-2017. Todo el mundo mejor. Quito: Senplades.

SENPLADES (2013). ¿Qué es el buen vivir? En: http://vimeo.com/70792366 (acceso 3 de febrero de 2014).

Huelva: CIM/FIUCUHU/Pydlos.

Unceta, Koldo (2011). "El buen vivir frente a la globalización”, en Centro Andino de Acción Popular. Acerca del Buen Vivir. Ecuador Debate N. 84. Quito: CAAP

Unceta, Koldo (2014). Desarrollo, postcrecimiento y Buen Vivir: debates $e$ interrogantes. Quito: Abya Yala.

Zizek, Slavoj (2014). Trouble in Paradise. From The End of History to The End of Capitalism. London: Penguin Books. 
El Sumak Kawsay y el Yasuní: contradicciones, disputas y esperanzas. Una alternativa al capitalismo

\footnotetext{
${ }^{1}$ En el PNBV se menciona el desarrollo de oleoductos y gasoductos, interconexión eléctrica, acueductos, líneas férreas (SEMPLADES 2013, 46), de tecnologías (65), del mercado (72), del sistema de refinación de hidrocarburos (76), de la industria (304), de la minería, de los recursos humanos, de polos industriales (76), de las tecnología de información y comunicación (100), del área rural (120), de lo urbano (142), de lo productivo y habitacional (149), de lo cognitivo (161), de lo científico (165), de lo emocional, intelectual y físico (190), del sector agropecuario y pesquero (233), del mercado de valores (304), de lo digital (320), de lo tecnológico (321), de la industria petroquímica (322), de la gran minería $(324,399)$, de lo turístico (394), de la industria farmacéutica (406), del capital humano (435).

${ }^{2}$ Según el PNBV, los "recursos naturales" son finitos (19, 82, 159, 227, 232), hay que gestionarlos eficientemente y optimizarlos $(26,44,46,52,75,147,222,237,253,317,381)$ y distribuirlos $(25,85)$, ordenarlos eficientemente (36), y se los considera no integralmente sino como bienes separados: recursos hídricos $(58,240,123,128,229,325,369)$, recursos humanos $(73,76)$, recursos genéticos $(74)$, recursos petroleros (75), recursos como riqueza $(79,81)$, recurso aire (230), la megadiversidad y biodivesidad como recurso $(222,283)$, recursos forestales $(234)$, recurso solar $(317)$, recursos minerales $(317)$, recursos auríferos (318), recursos ictiológicos (302), recursos biológicos "tales como alimentos frescos y procesados, bioenergías, productos farmacéuticos, biotecnología, bioquímica y biomedicina" (322), recursos marino-costeros (325), recursos de la biodiversidad (326), recursos de la órbita geostacionaria y el espacio radioeléctrico (343), recurso suelo (376), recursos eólicos, geotérmicos y petroleros (384).

${ }^{3}$ Constitución del 2008, Preámbulo, Artículos 10, 71, 72, 277.1, 389.

${ }^{4}$ Constitución del 2008, Artículos 66.12, 66.27, 275, 282.

${ }^{5}$ Constitución del 2008, Artículos 73, 83, 276.4, 290.2, 317, 319, 385, 387.3, 395.4, 399, 403.

${ }^{6}$ La Constitución hasta al ser humano considera como recurso (Art. 51, 191, 229), recursos renovables (Art. 57.6), recursos de la fauna y flora (Art. 57.12), recursos genéticos (Art. 57.12), los minerales, hidrocarburos, hídricos, biodiversidad y bosques como recursos energéticos (Art. 261.11), recursos naturales como recursos económicos (Art. 274), recursos del subsuelo (Art. 276), recurso natural como sector estratégico (313), recursos hídricos (Art. 318), recursos genéticos (Art. 318), los recursos naturales (Art. 408), recursos hídricos (Art. 411).

${ }^{7}$ Constitución del 2008, Artículos 72, 113.1, 152.2, 153 .

${ }^{8}$ Constitución de Bolivia de 2009, Artículos 8.II, 80.I, 289, 306, 313.

${ }^{9}$ https://www.youtube.com/watch? $\mathrm{v}=\mathrm{IFc} 1 \mathrm{topfPqM}$
}

Artigo recebido em 10 de março de 2017 e aceito em 22 de junho de 2017 